\title{
Energy efficient renovation of typical buildings in the subtropics
}

\author{
Elena Yurchenko ${ }^{1}$, Alexander Volkov ${ }^{1, *}$, and Asthik Kakosyan ${ }^{1}$ \\ ${ }^{1}$ Sochi State University, Ecology and Engineering Faculty, 354003, 94, Plastunskaya street, Sochi, \\ Russia
}

\begin{abstract}
The field of study is the experimentally justified choice of material for a single-layer, energy-efficient thermal protection of the exterior walls of typical buildings in the subtropics. A decrease in the vapor permeability of the mineral heat insulation at a humidity of more than $50 \%$ has been experimentally confirmed, and their loss of heatshielding properties during moistening has been substantiated. It is recommended to correct the vapor permeability values of external walls with multilayer heat protection with Rockwool due to a decrease in the diffusion resistance coefficient of the wet zone of the material compared to the dry zone. Based on a comparative analysis of the design parameters of the types of thermal protection, it is recommended to use thermal plasters as single-layer thermal insulation systems. The experimentally established value of open porosity of $83.1 \%$, for thermo-plaster based on foam glass, made it possible to choose protection against moisture in the form of penetrating Penetron waterproofing. The use of such protection reduced the value of open porosity of samples to $59.2 \%$ and eliminated the effect of condensate on energy efficiency when modernizing existing buildings.
\end{abstract}

\section{Introduction}

Energy consumption of buildings in Russia uses more than $40 \%$ of the generated thermal energy, which requires making energy-saving decisions in building reconstruction. For representatives of the last century 60-90-s model series, according to current standards, the thermal protection of vertical walling should be increased by 1.5-2 times, therefore, so the choice of materials is very important. As a rule, this problem is solved by multilayered structures with the use of Rockwool type insulation, fixed to the existing external walls' surfaces, with «Cerezit» type coatings on a synthetic mesh. The effectiveness of such system significantly depends on the quality of its installation and operation [1]. The installation is complicated by the construction of the walls themselves, which have significant wear of the joints between large panels and the material of the panels themselves - low-strength claydite-concrete. With insufficient quality of the multi-layer construction of

\footnotetext{
*Corresponding author: volkovsochi@gmail.com
} 
the "wet facade», the moisture condition of the insulation becomes unfavorable due to moisture, and the processes of diffusion and condensation increase. As a result of renovation instead of increasing its energy efficiency reduction occurs, decreasing durability of the material with the required 25 years to 7.5 years. In the future low maintainability of the multi-layer construction of thermal protection, due to the heterogeneity of the layers, will require the dismantling of the entire system and its replacement. At the observed sites in the city of Sochi, we identified defects in the installation (fig. 1) and operation (fig. 2) that are characteristic of a «wet facade». To eliminate the indicated drawbacks, it is possible to apply single-layer thermal protection from thermal plaster, which has uniform properties due to factory production in the form of dry mixtures. They are adaptable when mixed with water and applied to surfaces, maintainable in cases of local damage. Thermal plasters are widely used in Europe for the renovation of housing [2]. The dry mix of thermo-plaster based on foam glass is produced by «Runit» in St. Petersburg. Features of its application in a subtropical climate - the purpose of this study. During the process, it became necessary to experimentally confirm the reduction of the vapor permeability of the mineral foam insulation at a humidity of more than $50 \%$ in order to justify their loss of heat-shielding properties when wetted. A comparative analysis of the calculated parameters of multilayer and single-layer thermal protection systems was made. Experimentally, for subtropical conditions, those characteristics of thermo-plaster of the company «Runit» based on foam glass were studied, which helped to select its protection from the penetrating waterproofing «Penetron» against atmospheric, capillary and condensation moisture [3].

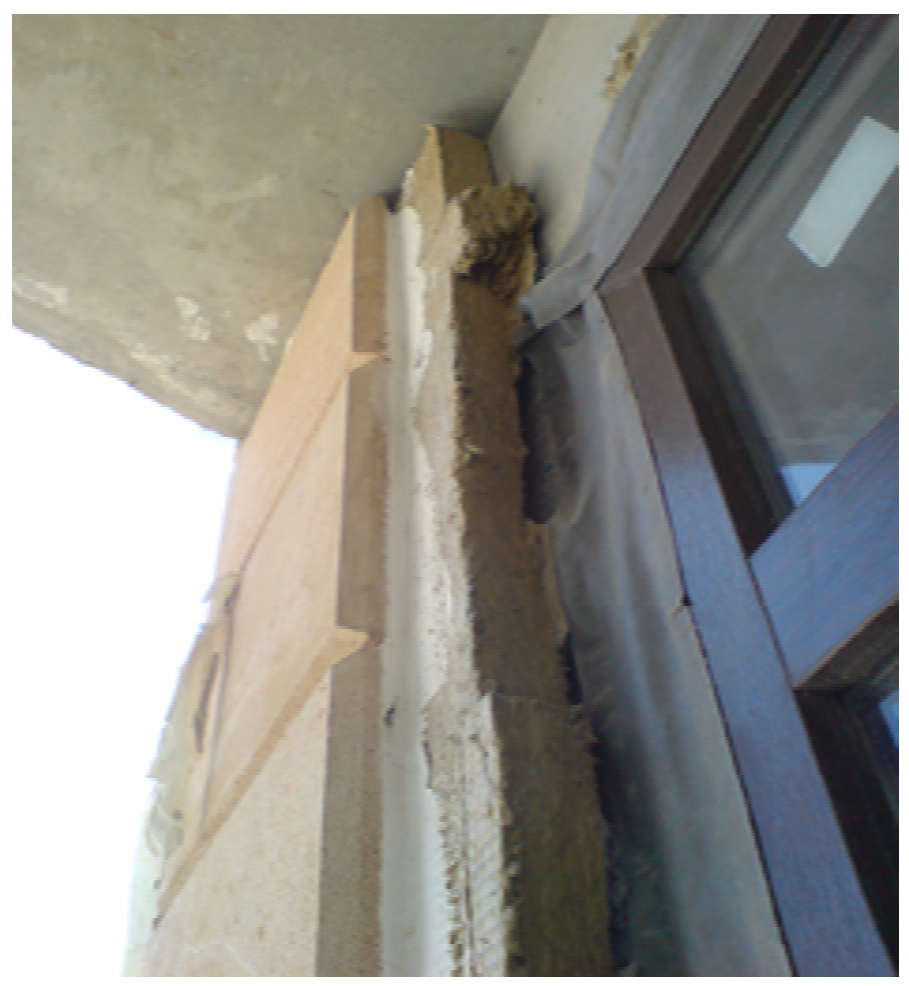

Fig. 1. Defects of installation of multilayer "wet facade". 


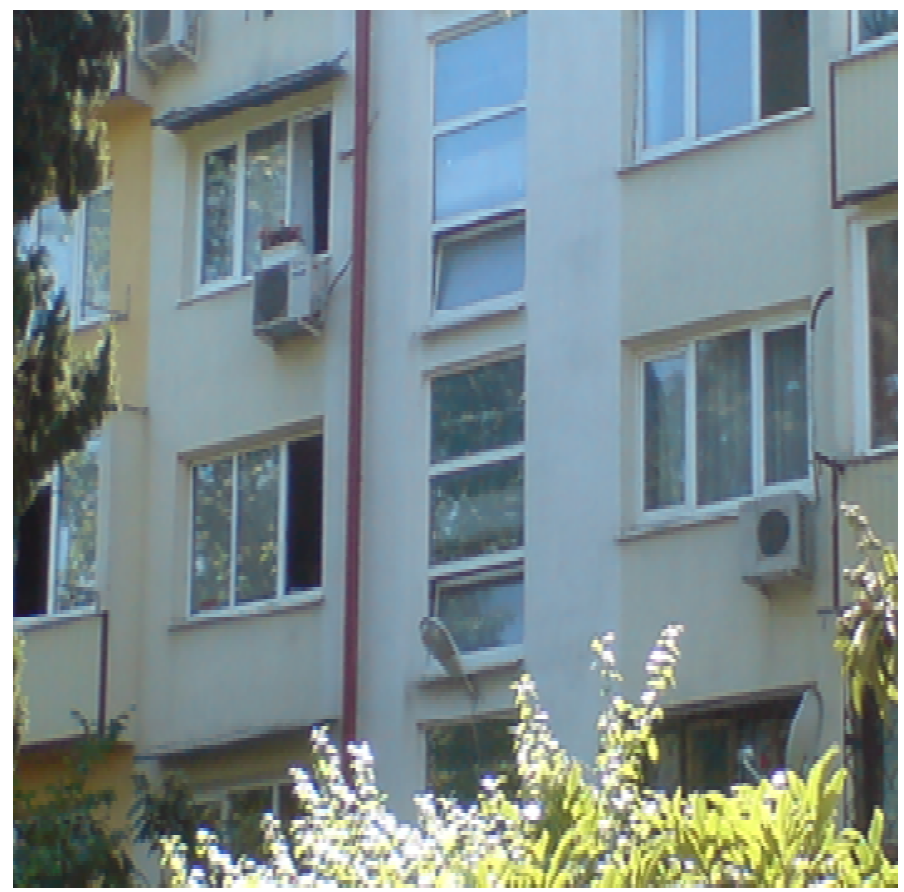

Fig. 2. Defects of operation of wet facade construction.

\section{Materials and Methods}

Experiments confirming the reduction of vapor permeability of mineral insulation with humidity over $50 \%$ were made for the design justification of the loss of its heat-shielding properties. Both standard and actual climatic parameters were measured during operation, temperature and humidity inside the premises of typical production houses were used. The internal air temperature in a typical series residential building is $18^{\circ} \mathrm{C}$, the relative humidity of the internal air is $60 \%$, the design temperature of the coldest five-day week of January is $3{ }^{\circ} \mathrm{C}$, the average relative humidity is $72 \%$, measured by experiments $-74 \%$, the humidity mode is normal; The humidity zone for Sochi is wet, the operating conditions of the enclosing structures are taken according to parameter $\mathrm{B}$. The mechanism of moisture transfer in the Rockwell porous material has been investigated according to the method of K. Shpeidel. During the application of which, the verification of K. Shpeidel was verified that the diffusion of water vapor through the porous material is similar to the capillary movement of moisture, and this fact must be taken into account when calculating the vapor permeability of materials. These studies were carried out in the Sochi State University laboratory for samples from «Rockwell», which is a layer of insulation for the «wet facade» structure, the most common in the repair of model series in the city of Sochi. Samples in the closet of the apartment in vapor-tight containers with tight sealing edges. Silica gel was poured into one container under the sample, and 5 grams of distilled water was poured into the other. In the experiments of K. Shpeidel, rooms with a relative humidity of $50 \%$ are recommended, as in ordinary rooms in Germany. But in the conditions of the city of Sochi, the relative humidity of the air in the apartments is much larger and is mainly $74 \%$. Since in a tank with silica gel, the relative humidity of the air should be close to $0 \%$, water vapor from the room should diffuse through the porous material into the tank. In a tank with distilled water, the relative air humidity should be close to $100 \%$, and water vapor from the 
tank should diffuse through the porous material into the room. If the diffusion resistance coefficients of both samples were equal, then in the room after some time equal humidity levels would be established, that is, $74 \%$, since the difference in partial pressures, the sizes of the samples are the same. The exact amount of water vapor that would diffuse from the water tank should diffuse into the silica gel tank. This process should not be affected by any deviations in the relative humidity of the air, or in the room temperature. The humidity of $50 \%$ in Shpeidel's experiments and $74 \%$ in us would prove that the diffusion resistance coefficients of the wet and dry zones of the porous material are equal. But the humidity in the closet of the apartment for 6 days increased to $85 \%$ and no longer increased for two days. This means that the sample with silica gel was under the influence of a partial pressure difference of $0.85 \mathrm{p}_{\text {sat }}$, and the sample with water under the influence of $0.15 \mathrm{p}_{\text {sat }}$. From this it follows that the ratio of the coefficients of vapor permeability will become

$$
\mu_{\text {dry }} / \mu_{\text {wet }}=0.85 / 0.15=5.7
$$

Therefore, the greater the equilibrium humidity in the premises exceeds $50 \%$, the diffusion resistance coefficient of the wet zone of the porous material will be less than the diffusion resistance coefficient of the dry zone of the material. The studied mechanism of moisture transfer qualitatively demonstrates that in conditions of air humidity in rooms greater than $50 \%$, the diffusion resistance coefficient of the wet zone of the insulation material will be less than the diffusion resistance coefficient of the dry zone, and water vapor will diffuse towards the room. This result is necessary to correct the vapor permeability calculations of the exterior walls of typical residential buildings, insulated with multilayer thermal protection with «Rockwool» for operating conditions in subtropical climate. Since the non-accumulation of vaporous moisture in the enclosure is a necessary condition for the design of thermal protection, its provision is operated on by the reciprocal of the resistance to vapor penetration of the layer, that is, the vapor permeability of the layer Gi. This value is not the amount of moisture that passes through a separate layer of the fence, but the «throughput» of this layer. If the individual layers in a multi-layered fence are arranged in order of increasing «throughput» from the inner surface of the fence to the outer Gint $<\mathrm{G} 1<\mathrm{G} 2<\ldots<\mathrm{Gext}$, then the vaporous moisture penetrated into the fence through the inner layer of Gint with increasing ease the power of increasing their «throughput». The value of Gi of an individual layer can be changed either by changing the layer thickness, or by choosing a material with a different coefficient of vapor permeability $\mu$ i. When taking into account the experimental data according to Shpeidel's method for the operating conditions of typical residential buildings, modernized «wet facade» expression

$$
\mathrm{G}_{\text {int }}=2.75>\mathrm{G}_{1}=0.39<\mathrm{G}_{2}=5.5<\mathrm{G}_{\text {ext }}=8.8 \mathrm{mg} /\left(\mathrm{m}^{2} \mathrm{hPa}\right)
$$

will become

$$
\mathrm{G}_{\text {int }}=2.75>\mathrm{G}_{1}=0.39<\mathrm{G}_{2}=5.5>\mathrm{G}_{\mathrm{ext}}=1.6 \mathrm{mg} /\left(\mathrm{m}^{2} \mathrm{hPa}\right) ;
$$

at the same time, the wall of the standard series, that has not been modernized with a "wet facade", has indicators

$$
\mathrm{G}_{\text {int }}=2.75>\mathrm{G}_{1}=0.39<\mathrm{G}_{\text {ext }}=5.5 \mathrm{mg} /\left(\mathrm{m}^{2} \mathrm{hPa}\right) .
$$

The features of operation in subtropical conditions led to the search for a single-layer thermal protection system, which excludes the above substantiated provisions. In accordance with the norms, a comparative analysis of the calculated parameters of multilayer and single-layer thermal protection systems was carried out, the thermal plasters of the company Runit based on foam glass were selected. Experimentally investigated those properties that helped pick up its protection from atmospheric, capillary and condensation moisture penetrating waterproofing «Penetron». 
Determination of water absorption was carried out on three samples of plaster «Runit» on the basis of foam glass

for samples - cubes with a facet of $5 \mathrm{~cm}$ by boiling them with water. The determination of the true density of the plaster samples was carried out by the pycnometric method based on measurements of the volume of liquid - distilled water displaced by the sample of the material from the vessel. As protection against atmospheric and capillary moisture, hardened samples from warm «Runit» plaster were covered with a penetrating waterproofing «Penetron» in accordance with the instructions for use (fig. 3).

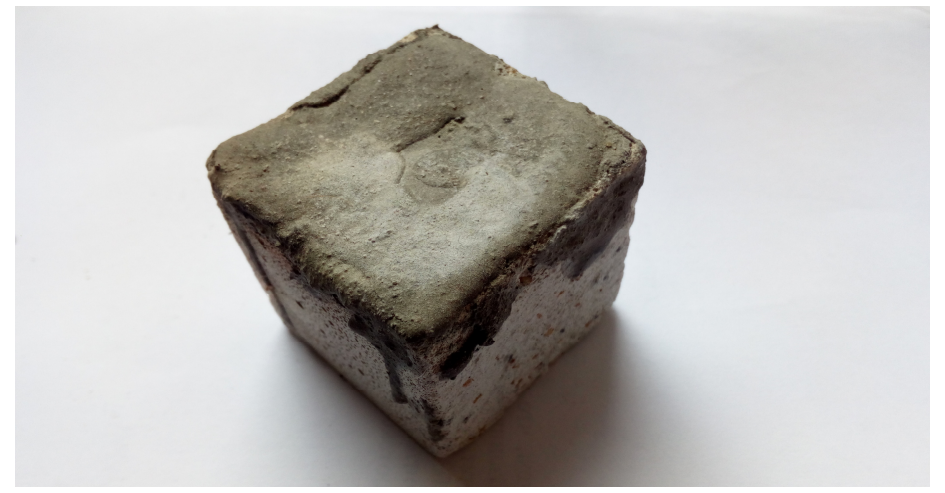

Fig. 3. The coating of plaster samples penetrating waterproofing «Penetron».

\section{Results}

The results of a comparative analysis of the calculated parameters for the heat transfer resistance [4] of standard series of houses in the city of Sochi before modernization and after the "wet facade» system prove the need for thermal protection, since this value increased more than 2 times from 0.83 to $1.98\left(\mathrm{~m}^{2 \circ} \mathrm{C}\right) / \mathrm{W}$, when using thermal plaster -1.8 $\left(\mathrm{m}^{2 \circ} \mathrm{C}\right) / \mathrm{W}$. However, when wetting the insulation of the «wet facade» system, the resistance to vapor permeability will increase to a value of $3.52 \mathrm{~m}^{2} \mathrm{hPa} / \mathrm{mg}$, which is more than the value for an unheated wall of $3.09 \mathrm{~m}^{2} \mathrm{hPa} / \mathrm{mg}$. Thus, instead of a warm compress for the wall, a «wet compress» is obtained. The position of the dew point is shown in figure 4 , and the vapor permeability characteristics in table 1 . 


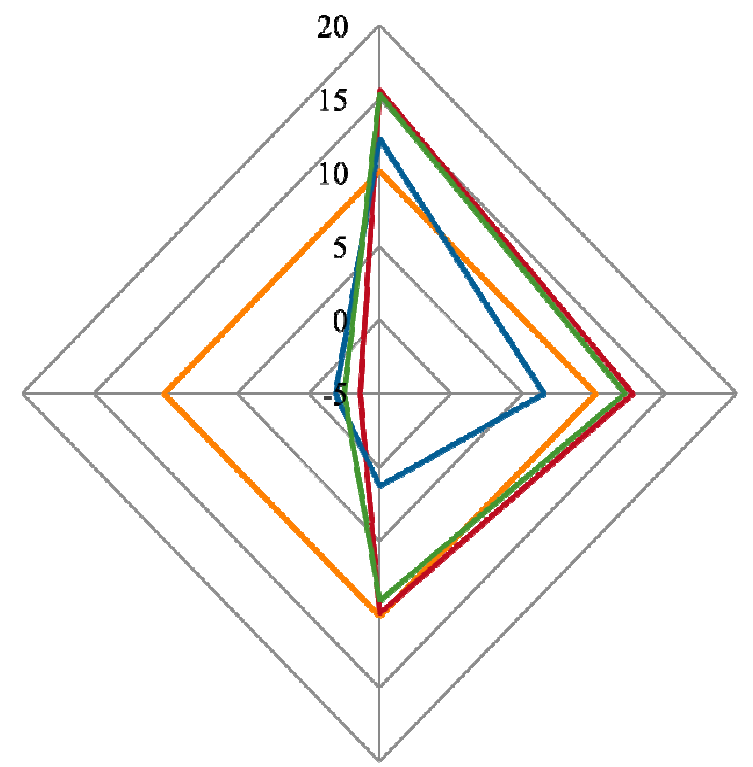

-Dew point temperature

- Temperature in repaired wall layers

- Temperature in unrepaired wall layers

- Temperature in layers of the wall with thermoplaster

Fig. 4. Sheet diagram of the position of the dew point over the layers of the repaired walls with the «wet facade» system, non-repaired walls and walls with thermal-plastered insulation.

The results of determining the water absorption of the samples of thermal plaster firm «Runit» on the basis of foam glass are presented in table 2 , the true density in table 3 .

The value of the apparent density $p_{\text {apparent }}=2.36 \mathrm{~g} / \mathrm{sm}^{3}$, open porosity $\mathrm{P}_{\text {open }}=83.1 \%$, led to the conclusion that it is necessary to protect the outer layers of thermal plaster with penetrating waterproofing «Penetron». This protection allowed to reduce the value of open porosity to $59.2 \%$, which, moreover, the use of Penetron increased the compressive strength from 1.6 $\mathrm{MPa}$ to $1.72 \mathrm{MPa}$. Economic calculations on local estimates for the implementation of the "wet facade» system in prices of 2015 showed approximately the same cost as compared with the use of thermal plaster. 
Table 1. Design characteristics of external walls on vapor permeability for applied with.

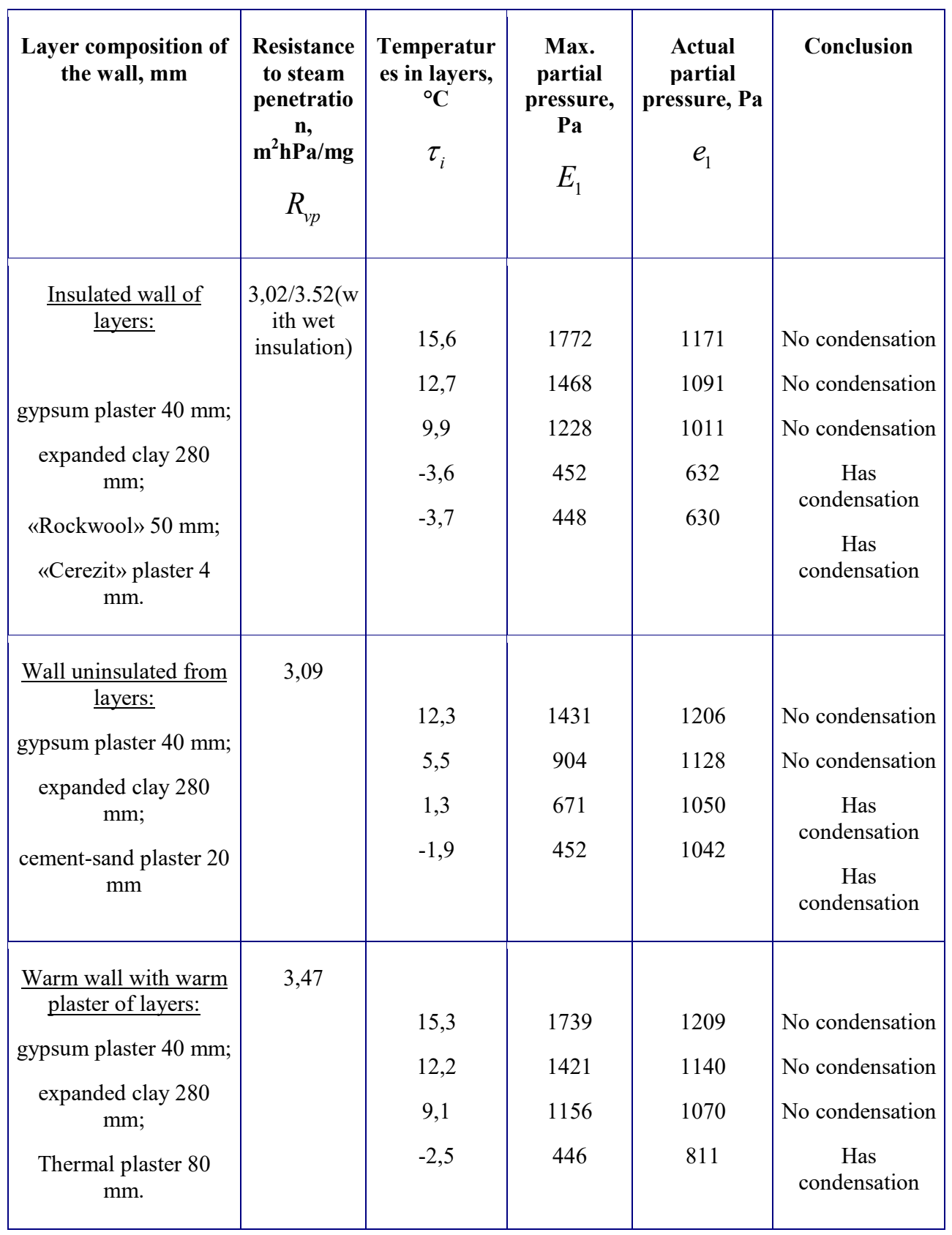


Table 2. Test results of water absorption of samples of plaster based on foam glass.

\begin{tabular}{|c|c|c|c|c|}
\hline $\begin{array}{c}\text { Sample } \\
\text { number }\end{array}$ & $\mathbf{m}_{\text {wet }}, \mathbf{g}$ & $\mathbf{m}_{\text {sat }}, \mathbf{g}$ & $\begin{array}{c}\text { Sample volume } \\
\mathbf{V}, \mathbf{s m}^{\mathbf{3}}\end{array}$ & $\begin{array}{c}\mathbf{W}_{\mathbf{m}} \\
\mathbf{\%}\end{array}$ \\
\hline 1 & 90,98 & 134,33 & 125 & 47,6 \\
\hline 2 & 82,64 & 127,6 & 122,5 & 54,4 \\
\hline 3 & 86,09 & 129,2 & 120,1 & 50,1 \\
\hline
\end{tabular}

Table 3. The determination of the true density of samples of plaster based on foam glass.

\begin{tabular}{|c|c|c|c|c|c|c|c|c|}
\hline \multirow{2}{*}{$\begin{array}{c}\text { Pycno- } \\
\text { meter } \\
\text { number }\end{array}$} & \multicolumn{4}{|c|}{ Pycnometer weight, $g$} & \multirow{2}{*}{$\begin{array}{c}\text { Sample } \\
\text { weight } m \text {, } \\
\quad \mathrm{g} \\
\left(\mathrm{m}_{2}-\mathrm{m}_{1}\right)\end{array}$} & \multirow{2}{*}{$\begin{array}{c}\text { Sample } \\
\text { volume, } \\
\mathbf{v}, \mathbf{s m}^{3}\end{array}$} & \multirow{2}{*}{$\begin{array}{c}\begin{array}{c}\text { True } \\
\text { density, }\end{array} \\
\mathbf{p}_{\text {tr }} \mathbf{k g} / \mathbf{m}^{3}\end{array}$} & \multirow{2}{*}{$\begin{array}{c}\text { Average } \\
\text { true } \\
\text { density } \\
\text { p }_{\text {true }}\end{array}$} \\
\hline & $\begin{array}{c}\text { Empt } \\
\mathbf{y}, \mathbf{m}_{1}\end{array}$ & $\begin{array}{c}\text { Empty } \\
\text { with } \\
\text { sample } \mathbf{m}_{2}\end{array}$ & $\begin{array}{c}\text { With } \\
\text { sample } \\
\text { and water } \\
\mathbf{m}_{4}\end{array}$ & $\begin{array}{c}\text { With } \\
\text { water } \\
\mathbf{m}_{3}\end{array}$ & & & & \\
\hline 1 & 6 & 11,14 & 20,65 & 18,5 & 5,14 & 7,304 & 0,704 & 0,714 \\
\hline 2 & 6 & 10,88 & 20,33 & 18,5 & 4,88 & 6,73 & 0,725 & \\
\hline
\end{tabular}

\section{Discussion}

Experiments and calculations confirm the feasibility of carrying out insulation of the walls of residential buildings of standard series in the city of Sochi. However, the applied multilayer heat insulation composition «wet facade» works only with its high-quality installation, which is noted in research [5] and it is proposed to monitor thermal and physical characteristics of heaters to prevent condensation in the thermal protection layer, which is clearly demonstrated. The use of heat-insulating plasters during renovation allows us to avoid the drawbacks of the "wet facade», which contains slab insulation, which does not adhere to the existing wall structure, and is unable to fill the joints between the panels damaged during operation. In addition, using plaster does not require leveling the surface of existing panels. Obviously, for this reason, research in the field of creating optimal compositions of thermal plasters continues to achieve the optimal combination of thermal and mechanical properties during renovation, as evidenced by the history of the development of thermal insulation materials described in. In Sochi, there are already houses with thermo-plaster insulation. Externally, the «wet facade» and the facade with thermal plaster do not differ. Protection of thermal plaster on the basis of foam glass in the form of a plaster by waterproofing «Penetron» will save this single-layer insulation from atmospheric, capillary and condensation moisture. 


\section{Conclusions}

Single-layer thermal insulation with thermoplastic material allows avoiding a reduction in vapor permeability of external walls when the operating environment humidity is more than $50 \%$, which is observed when using a multilayer composition with a mineral-wool insulation. Experimentally confirmed the reduction of the diffusion resistance coefficient of the wet zone of the Rockwool insulation material compared to the dry zone.

An energy-efficient single-layer material was chosen - a thermal plaster based on «Runit»'s foam glass. A comparative analysis of heat transfer resistances for model series of houses in the city of Sochi, before and after modernization, proved the need for its use. Thermal protection with the multilayer "wet facade" system increased this indicator by more than 2 times from 0.83 to $1.98\left(\left(\mathrm{~m}^{2} \bullet{ }^{\circ} \mathrm{C}\right) / \mathrm{W}\right)$, and thermal plaster to $1.8\left(\left(\mathrm{~m}^{2} \bullet{ }^{\circ} \mathrm{C}\right) /\right.$ $\mathrm{W})$. The ineffectiveness of the "wet facade" system was revealed with the moisture of the insulation to increase the resistance to vapor permeability to a value of $3.52\left(\mathrm{~m}^{2} \cdot \mathrm{h} \cdot \mathrm{Pa} /\right.$ $\mathrm{mg}$ ). The obtained value exceeds the figure for the wall before the modernization of 3.09 $\left(\mathrm{m}^{2} \cdot \mathrm{h} \cdot \mathrm{Pa} / \mathrm{mg}\right)$. The choice of single-layer thermal insulation using a glass-based foam glass of a firm with moisture protection by Penetron penetration waterproofing is substantiated. The energy efficiency of such a modernization of typical building walls will ensure the preservation of the heat transfer resistance index of walls $1.8 \mathrm{~m}^{2} \cdot{ }^{0} \mathrm{C} / \mathrm{W}$ in subtropical climate. Further research for the application of thermal plasters will be continued in the area of increasing their strength by searching for additives from fiberglass or fiberglass reinforcement to increase adhesion to existing wall structures during renovation.

\section{References}

1. V.N. Morgun, L.V. Morgun, I.A. Cherenkova, , H. con., 4, 21-24 (2015)

2. M. Davraz, L. Gündüz, E. Başpınar, J. Eng. Sci. Des., Vol.1/Issue 3, 150-155 (2011).

I. Igoumenidis, Th. Pl. Tack. D. \& Th. Perf. Cum. Cott., Cons. \& Her. J., https://www.ecologicalbuildingsystems.com/docs/Conservation_\&_Heritage_Magazine _Glen_Cottage\%20_Diasen_Final.compressed.pdf, (2018)

3. Advantages of the Penetron Integral Waterproofing System, ICS Pen. In. Lim., https://www.penetron.gr/index.php/en/products/brochures/494-advantages-of-thepenetron-integral-waterproofing-system-en/file

4. F. Ascione, N. Bianco, R. F. De Masi, F. de'Rossi, \& G. P. Vanoli, Appli. Ener., 113, 990-1007 (2014)

5. Vrána, Impact of moisture on long term performance of insulating products based on stone wool, licentiate thesis, KTH - The Royal Institute of Technology (Stockholm 2007) 